\title{
HAROLD AND THE PURPLE CRAYON
}

\author{
DOMINIQUE BOREL
}

Some months ago professor Lizhen Ji asked me to write an article about my father and his relationship to fiction. I thought, at the time, it was inappropriate so I declined. As time went by, however, the idea started to germinate and gradually to intrigue me.

The first gift that I remember my father giving me was for my fourth birthday It was a book. We had just come to Princeton to settle. My father was off giving a seminar or conference, I think, in Chicago. My mother picked up something at the post office. On the way back she opened the envelope and couldn't resist giving me the book immediately, "Harold and The Purple Crayon", which I still have. That was the first of many books he was to give me. I loved the book and just reread it before writing this reminiscence. I had to laugh because it is about a boy who creates his world by drawing what he wants in it with his purple crayon - not unlike what my father was doing with his chalks and pencils. My perception of math as a child was that it was black and white, cold and gray. It felt like a very secret world and gave me trouble from the start, beginning with subtraction. I was much happier in what I perceived to be the colorful world of literature and art. There is some truth to that color of course, but in fact I am sorry that my father did not communicate to me earlier the enormous imagination, magic and intuitive components also involved in higher math. It would have meant a great deal to me. I came to understand this only much, much later.

In any case my colorful world was far from being a world he was alien to. As a child, and like many of his colleagues, my father was a voracious reader. In terms of fiction, one of his absolute passions was Sherlock Holmes. Another was Alexandre Dumas. As an adult he felt that he no longer had much time for fiction, but he reminisced often about his old childhood friends. Before even introducing me to "Harold", he used to walk with my sister Anne and I from the Institute to the Project. The little tiny bridge on the path was his opportunity to tell us the story of Billy Goat Gruff and to scare us with deep voiced imitations of "Who's walking over my bridge". Of course my mother Gaby, who is full of imagination and fancy, was also adding to the literary roster by inventing stories to "read" to me from pieces of toast that she folded in half like a book during breakfast, as well as reading to me the incessantly requested Beatrix Potter favorites.

As a child I began a lifelong romance with drama and would invent plays or enact fairy tales to put on for whoever could bear it. Most often I would cast myself in the role of the witch and my sister as Gretel or some other such character (she's younger) making her go through the trials of being in and out of the oven or whatever. At twelve, I decided that I wanted to do more scripted things seriously. My father was thrilled. He had been a movie buff as an adolescent, a period which he considered (and he is not alone) to be the golden age of cinema, He drank in all the fabulous Hollywood movies from the 30's - the Garbos, Ingrid Bergmans, and the earlier classic gems starring Buster Keaton (his favorite) and Charlie Chaplin, 
and, oh, how could I forget - The Marx Brothers! French cinema was producing masterpieces such as "La Grande Illusion". Jean Gabin and Louis Jouvet were at the top of their game. He told me so many times how grateful he was to accidentally have been an adolescent during the greatest period in cinematic history. This he definitely communicated to me. He had a fine tuned sense of character and of acting. Nothing much escaped him. When I started to act seriously he was one of my absolute favorite audience members. Solid support, eager anticipation unmitigated enthusiasm (if deserved) with totally lucid criticism. It was immensely satisfying and great fun to have him taking in the work and to discuss it with him after. He knew the literature, understood the characters and recognized truth in acting and always reaped such pure enjoyment as a spectator. In fact I put on a children's play in June of 2003 in New York. It was with French speaking children and the play was "Dr. Knock", one of my father's old favorites, the original having starred Louis Jouvet - a production he saw with his mother in Geneva. He was in a great deal of pain, though he didn't speak about it and no diagnosis had been delivered yet. I felt guilty for having talked my father into coming into New York, and was watching him from the sidelines as the curtain went up. I needn't have worried. His face broke into an immense smile as soon as the action started. A few days later he made it into New York once again. We had a date to see a new Woody Allen play.

When my father was staying at home that summer, I started to read to him. It was a Dumas fils book that he had missed, suggested by Sylvie Weil, "The Mohicans of Paris". I would read him one, two maybe three chapters at a time. Like much Dumas the chapters are perfectly proportioned for this type of undertaking as they were originally fashioned for serial publication. As sick as he was, he was still as always ahead of the game. Dumas systematically introduces countless subplots, plot twists and weaves a tapestry of characters with unending exits, entrances and surprise connections. These must be kept track off. When I would pick up the book to read the next chapter Armand would invariably say (with total accuracy), "so in the last chapter we had...". The last two chapters I read to him were just a few hours before he died.

It was also during this period that the 5th Harry Potter book came out. My father, having read the Harry Potter books, was a great supporter of J. K. Rowling. He wrote her in late July (2003) to congratulate her on significantly raising the literacy rate among youngsters, a literacy rate which he felt had fallen sharply "from being a zombie 20 hours or more in front of the TV or using computers". Armand also drew a parallel between having to keep track of the plethora of intrigues and characters in "Harry Potter", contributing to the development of a quickness of mind, with the alertness of the average Indian person as a result of exposure to the "The Ramayana" and "The Mahabharata", "epics completely embedded in the culture and familiar from childhood by oral tradition, reading, puppet theatre and outdoor theatres".

After my father died last August 11th we slowly began the process of going through his office. One of the things I came across was a letter he had written to the local paper ("The Trenton Times") in '92, involving his old friend Sherlock Holmes. Their columnist, Katie McCartin, had attended his lecture on Math and Culture. I quote a small portion that makes clear the nature of their exchange. 
Armand wrote: "I was quite impressed by your account, based only on your Notes and not on any text. It is witty and conveys a lot of what I was trying to express. The only sad feature is that you unwittingly cast aspersions in my knowledge of the Sherlock Holmes saga, by making me say that Reichenbach Falls had been the scene of S.H.'s downfall. I did not say anything of the kind. In fact I offered no comment as to what happened there. If I had, I would have..." and he then briefly explains what Conan Doyle did with Holmes. "...now I will be stamped forever as ignorant in the finer points of the S.H. lore, he continues adding jokingly, "It hurts."

Ms. McCartin responded with a lengthy column, which ended with, "...Why did I give such an obscure point so much thought? It's just that, as much as I love Doyle's brilliant and cocaine-addicted detective, I have never respected the author's decision to bring Holmes back from the dead just because he got bad press for killing him in the first place..." and she continues "After Borel's talk. I thought, here's my chance to make a small, if invisible statement about the balance between creative integrity and public pressure. I just can’t believe anybody caught me. Sorry, Professor".

In closing, I will simply say, that part of my initial reluctance to write anything on this or anything else relating to my father was, one: a desire to respect his wishes that the personal not be mixed in with his math world, two: that in writing a pastiche triggered by the idea of "Borel and fiction", I inevitably am leaving out much which he either never spoke to me about or has slipped my mind thereby giving perhaps an inaccurate glimpse of "the topic" and three: the fact that to bring up these thoughts and memories is bittersweet for me. He is not here to share and laugh about them with me, to expand with a point or fill in the gaps. We never got to finish the Dumas book together. Writing this reminiscence has made me miss him only more. 
